\title{
De un modo de relacionar dos elementos contrarios a la mediación o acerca de la aproximación histórica al concepto mediación ${ }^{*}$
}

\author{
(a) \\ Lina María Grisales Franco ${ }^{* *}$ \\ Elvia María González Agudelo
}

Recibido: 20 de septiembre de 2010 Aceptado: 30 de septiembre de 2010

\begin{abstract}
Resumen
Con un enfoque hermenéutico se aproxima históricamente al concepto mediación, con el fin de comprender los sentidos que se han ido incorporando al concepto a lo largo de la historia y desde diversos ámbitos. Desde la antigüedad habita la idea de la mediación, como un modo de relacionar dos elementos contrarios, pero es hasta principios del siglo XIX cuando (probablemente) aparece el concepto mediación con el pensamiento de Hegel. Posteriormente, aportes desde áreas como la psicología, la comunicación social, el derecho y la educación han contribuido a su conceptualización, para entenderlo y comprenderlo como un proceso dialéctico que busca instaurar, con la ayuda de un medio (un tercero) y en el marco de una cultura, una lógica común que posibilite la comunicación entre dos partes que tienen lógicas y formas diferentes de comunicarse.
\end{abstract}

Palabras clave: mediación, comunicación, acuerdo, contrarios, dialéctica.

Este artículo de investigación científica y tecnológica hace parte de la investigación "Desde la pregunta en tanto mediación, hacia la traducción como principio didáctico de la educación superior.

Doctora en Educación. Profesora Departamento de Formación Universidad de Antioquia, Medellín, Colombia. Magíster en Salud Pública, Especialista en Auditoría en Salud, specialista en Gerencia de Laboratorios, Bacterióloga y Laboratorista Clínico. Correo electrónico: lgrisales@udea.edu.co

Doctora en Ciencias Pedagógicas, Magíster en Educación: énfasis en currículo, Especialista en Literatura Latinoamericana, Licenciada en Educación: Español y Literatura. Docente Facultad de Educación Universidad de Antioquia, Medellín, Colombia. Coordinadora de la línea Didáctica Universitaria en el Doctorado en Educación de la Facultad de Educación de la Universidad de Antioquia, Coordinadora del Grupo de Investigación DIDES. Correo electrónico: egonzal@ayura.udea.edu.co 


\title{
From a way of relating two elements opposed to mediation or about a historical approach to the mediation concept
}

\begin{abstract}
This article is about historic approximation to mediation concept, which under approach hermeneutic understands the senses that have gone incorporating to the concept along the time and since diverse areas. Since antiquity inhabits the mediation idea, like a way to relate two contrary elements, but is to beginning of the 19th century when (probably) the concept mediation appears with the thought of Hegel. Subsequently, contribute from areas as psychology, social communication, law and education have contributed to their conceptualization, to understand it like a dialectical process to establish, with the aid of a medium (a third) and in the framework of a culture, a common logic that enable the communication between two parts that have logic and different forms from being communicated.
\end{abstract}

Key words: mediation, communication, agreement, opposite, dialectic. 


\section{Introducción}

El artículo es parte del trabajo Desde la pregunta en tanto mediación, hacia la traducción como un principio didáctico en la educación superior, investigación que busca instaurar en el campo de la didáctica universitaria, la traducción de saberes como un principio didáctico, la cual se presume está mediada por la pregunta. Entonces, como parte de la investigación, se hizo una aproximación histórica al concepto mediación para entender y comprender los sentidos que se han ido incorporando al concepto a través del tiempo y desde diversos campos del saber, para ser interpretados en el contexto de la pregunta y de la traducción de saberes en la enseñanza superior.

\section{Metodología}

En consonancia con la metodología de la investigación, la aproximación histórica al concepto mediación se realizó con un enfoque hermenéutico, en donde la pregunta que orientó la comprensión fue: ¿qué es mediación? Para dar respuesta a esta pregunta se aclara el significado etimológico de la palabra y se indaga por su uso en el lenguaje cotidiano, se va a los textos especializados para detectar cuándo la palabra empieza su uso como término en el lenguaje científico hasta que se instaura como concepto cuando es usada por una escuela de pensamiento específico. Así, se muestra su desarrollo en el tiempo y por medio de un proceso continuo de análisis, reflexión, comprensión e interpretación de textos y de autores, se postula una definición a la luz de la investigación, definición que guarda el sentido de la síntesis y del acuerdo al que se llegó en torno a la mediación.

\section{Resultados}

Etimológicamente las palabras mediación y mediador se derivan de mediar, la cual viene del latín mediare, de medius: medio (siglo XV) que significa "interceder", "terciar". Interceder viene del latín intercere: colocarse en medio, intervenir (siglo XV) y significa "intervenir a favor de una persona". Así, desde la etimología de la palabra, la mediación guarda el sentido de ser una acción, en tanto es una intervención de un medio, que busca interponerse entre dos que riñen para componer alguna disputa o discordia. En las entrañas de la palabra habitan, pues, el conflicto y la composición, en tanto acuerdo.

Si se parte que el conflicto es connatural al ser humano, se puede decir que la práctica de la mediación es tan antigua como el hombre. Sin embargo, la teorización de este concepto solo se vislumbra en tiempos contemporáneos. No obstante, desde la Antigüedad en algunos filósofos como Platón (427-347 a. C.) y Aristóteles (384-322 a. C.) y en San Agustín de Hipona (354-430) se percibe la idea de mediación como un modo de relacionar dos elementos distintos. Por ejemplo, en el diálogo de Platón, Timeo o de la Naturaleza (360 a. C., aproximadamente), la idea de mediación está en la actividad del demiurgo:

De la esencia indivisible y siempre la misma, y de la esencia divisible y corporal formó [Dios] combinándolas una tercera especie de esencia intermedia, que participa a la vez de la naturaleza de lo mismo y de la de lo otro, y así se encuentra situada a igual distancia de la esencia indivisible y de la esencia corporal divisible. Tomando después estos tres principios hizo con ellos una sola especie, uniendo a viva fuerza la naturaleza rebelde de lo otro con la de lo mismo. Mezclando a continuación lo indivisible y lo divisible con la esencia compuso con las tres cosas un solo todo, que dividió finalmente en tantas partes como le convenía, cada una de las partes contenía a la vez parte de lo mismo, de lo otro y de la esencia [...] (Platón, 1984:§27-33).

De esta forma la idea de mediación se instaura en la "tercera especie de esencia intermedia" que, a la vez, porta algo de lo uno y de lo otro y que, además, se ubica a igual distancia de lo uno y de lo otro, para componer un "solo todo" con las esencias contrarias - de ahí la naturaleza dialéctica de la mediación-. La mediación porta así el sentido de ser una actividad de un medio que lleva partes en conflicto, para conducir a una disposición nueva de estas partes respecto a un todo, también creado por la acción mediadora. 
Por su parte, aproximadamente en el año 335 a. C., Aristóteles desarrolla por primera vez, en el Órganon, la estructura formal de la lógica. Específicamente en el libro Analítica primera trata la doctrina del silogismo, como una forma de razonamiento deductivo. El llamado "término medio" en el silogismo ejerce una función mediadora en el razonamiento, por cuanto hace posible la conclusión a partir de la premisa. Para Aristóteles

... un silogismo es un conjunto de palabras o locuciones en el que, al hacerse determinadas asunciones, se sigue necesariamente, del hecho de haberse verificado de tal manera determinada todas las asunciones, una cosa distinta de la que se había tomado. Por la expresión "del hecho de haberse verificado de tal manera determinada las asunciones" quiero decir que es por causa de ello que se sigue la conclusión, y con esto significo que no hay necesidad de ningún otro término para hacer que la conclusión sea necesaria (Aristóteles, 1975:98).

Y más adelante agrega:

... cuando tres términos están, de tal manera, relacionados que el último está completamente incluido o contenido en el término medio, y el término medio está incluido o excluido totalmente del primero, de manera necesaria debemos admitir un perfecto silogismo entre los extremos. Significo por término medio aquel que es contenido en otro y contiene a otro en sí mismo y que, además, es medio por su posición; y significo por extremos aquel que está contenido en otro y aquel en que otro está contenido [...] (Aristóteles, 1975:101).

Mientras con Platón la idea de mediación se ubica en la esencia intermedia necesaria para componer un solo todo, con Aristóteles, esta idea se sitúa en el "término medio" como aquel que relaciona dos extremos o premisas para llegar a "una cosa distinta" o conclusión. El término medio está contenido en otro (en la premisa) y, a la vez, contiene a otro en sí mismo (la conclusión), lo cual le da la naturaleza relacional a la mediación. Por lo tanto, en la idea de mediación subyace el sentido de la relación de contrarios -o de enlace- para conducir al establecimiento de una cosa diferente de la que se ha partido.

Posteriormente, en la Antigüedad tardía, una idea semejante se observa en San Agustín de Hipona, padre de la iglesia latina, quien en su texto Confesiones (escrito entre los años 397-400) se refiere al Carácter del verdadero mediador entre Dios y los hombres (libro II, capítulo XLII). Al respecto señala:

Pero era menester que el mediador entre Dios y los hombres tuviese algo en que fuese semejante a Dios, y algo también en que fuese semejante a los hombres; porque si en todo fuera semejante a los hombres, estaría muy apartado de Dios; y si en todo fuera semejante a Dios, estaría muy alejado de los hombres, y así no podría ser medianero (San Agustín, 1824:219).

De este modo, la idea de mediación se ubica entre dos contrarios (Dios y el hombre), los cuales, a su vez, son contenidos en ella. Pero al igual que la idea de mediación que venía desde la Antigüedad clásica, en tanto la mediación dispone una cosa nueva, con San Agustín, la acción del mediador busca componer la relación entre Dios y los hombres, en tanto intercede a favor de los más desfavorecidos para alcanzar la vida y la paz eterna. De acuerdo con San Agustín:

Este mediador entre Dios y los hombres es el hombre Jesucristo, que se manifestó mediando entre los pecadores y mortales, y entre el que esencialmente es justo e inmortal: conviniendo en lo mortal con los hombres, y en la justicia y santidad con Dios, para que supuesto que la vida y la paz eterna es la paga y estipendio de la santidad y justicia, lograse con la justicia y la santidad en que convenía con Dios que cesase la sentencia de muerte fulminada contra los pecadores e impíos, a quienes justificó, y cuya muerte quiso padecer como ellos. (San Agustín, 1824:220-221).

Se percibe entonces, que en la Antigüedad la idea de mediación se estableció como un modo de relacionar contrarios: con Platón, la esencia intermedia relaciona la esencia indivisible y la esencia divisible; con Aristóteles, el término medio relaciona la premisa y la conclusión; y con San Agustín, Jesucristo relaciona a Dios y a los 
hombres. Así, en la idea de mediación de esta época se aloja el sentido de ser una acción que sirve de intermedio entre dos términos o dos seres considerados como dados independientemente de esa acción.

Pero también, la idea de mediación que habita en la Antigüedad es la de ser una acción que sirve de intermedio entre un término o un ser del cual se parte, y un término o un ser al cual se llega, siendo esa acción productora del segundo, o por lo menos condición de su producción, como se interpreta en el "todo" de Platón, en la "conclusión" de Aristóteles y en "la paz y vida eterna" de San Agustín. Pero ċcuándo esta idea de mediación que aloja los sentidos de la dialéctica y de la composición pasa a ser un concepto?

Posiblemente, estas ideas en torno a la mediación permanecieron durante la Edad Media y la modernidad, hasta cuando el filósofo alemán Georg Wilhelm Friedrich Hegel (1770-1831), a principios del siglo XIX presenta el texto Enciclopedia de las ciencias filosóficas (1817) en el cual expone que el conocimiento de la verdad es un conocimiento inmediato, absolutamente inicial y al mismo tiempo un conocimiento mediato (Hegel, 1968:64). Se presume, entonces, que es con Hegel que se pasa de la idea al concepto mediación, particularmente desde una perspectiva dialéctica.

Para Hegel "el saber inmediato debe ser tomado [...] como un hecho. Con ello pasamos al terreno de la experiencia [...]" (Hegel, 1973:\$66). Y entiende la mediación como "un comienzo y un progreso hacia un segundo término, de modo que esto, lo segundo, sólo es en tanto se ha llegado a él a partir de otro que le es opuesto [...]" (Hegel, 2006:42). De modo que con la mediación se llega a algo nuevo a partir de un contrario. La relación entre lo inmediato y lo mediato es ejemplificada por Hegel de la siguiente manera:

El matemático, como todo el que está experto en una determinada ciencia, tiene inmediatamente presentes soluciones, a las cuales ha sido conducido por un análisis muy complicado; todo hombre culto tiene inmediatamente presentes en su saber una cantidad de puntos de vista y de principios generales que no se han formado sino por una multiplicada reflexión y por una larga experiencia de la vida. La facilidad a que se llega en una rama del saber, en un arte, en una capacidad técnica, consiste precisamente en tener, cuando se presente la ocasión, inmediatamente y en la propia conciencia $[\ldots]$, aquellos conocimientos y modos de acción. En todos estos casos la inmediatividad del saber, no sólo no excluye su mediación, sino que la una y la otra están de tal modo unidas, que el saber inmediato es producto y resultado de aquel otro saber mediato (Hegel, 1973:§66).

Por eso para Hegel la mediación es comienzo y progreso, ya que todo saber inmediato fue primero un saber mediato, es decir, fue un saber reflexionado desde el cual se conduce a su inmediatez. De acuerdo con Ferrater,

Hegel concibe el conocimiento mediato en relación con su idea de la reflexión. Lo mismo que la luz es reflejada por un espejo y vuelve a su fuente, el pensamiento es también reflejado al rebotar sobre la realidad o las cosas en su "inmediatez". Se convierte entonces el saber mediato o "reflexivo". En este sentido el saber mediato es superior al inmediato. Pero en otro sentido el saber inmediato es superior al mediato, si bien entonces la inmediatez de que se trata no es ya la de las cosas que están simplemente "ahí", sino la de las cosas en su conexión racional con el Todo (Ferrater, 1994: 2348).

Se entiende entonces la mediación, ya no sólo como la relación de dos términos opuestos que están dados independientemente, sino como el elemento mismo, la acción del medio, desde la cual se deriva el segundo término (lo mediato). ¿Sera entonces, que el sentido de la composición o del acuerdo que habita en las entrañas del concepto, hace referencia a lo mediato? ¿Será la creación de la cosa nueva algo mediato, algo reflexionado? Para Hegel, el primer término está dado (lo inmediato), pero el segundo término deriva de éste y de su mediación: "[...] Si yo estoy en Berlín, esta presencia mía inmediata fue mediada por el viaje que hice para llegar a Berlín [... ]" (Hegel, 1973:§66). Mediato significa pues, que está en relación con otro término (y especialmente 
que deriva de otro término) por intermedio de un tercero (la mediación); significa condicionado, dependiente de otra cosa.

Este pensamiento de principios del siglo XIX llega al psicólogo bielorruso Lev Semiónovich Vygotsky (1896-1934) un siglo más tarde, cuando en la década de 1920, por influencia de Carlos Marx, trata de relacionar el materialismo dialéctico con cuestiones psicológicas. Así se va introduciendo el concepto mediación en el campo de la psicología, con grandes repercusiones en el ámbito de la educación.

Aunque en Vygostky no se percibe claramente la definición del concepto mediación, el concepto es empleado repetidamente en el texto El desarrollo de los procesos psicológicos superiores (publicado alrededor de 1924). Para Vygostky la mediación está ligada al empleo de signos (como el lenguaje, la escritura, los números) para realizar operaciones psicológicas superiores. Al respecto señala lo siguiente:

Toda forma elemental de conducta presupone una reacción directa a la tarea impuesta al organismo (que puede expresarse mediante la fórmula simple de $\mathrm{S} \rightarrow \mathrm{R}$ ). Sin embargo, la estructura de las operaciones con signos requiere un vínculo intermedio entre el estímulo y la respuesta. Este vínculo intermedio es un estímulo (signo) de segundo orden introducido en la operación, donde cumple una función especial; crea una nueva relación entre S y R. [...]. Este signo posee al mismo tiempo la importante característica de invertir la acción (es decir, opera en el individuo, no en el entorno). Por consiguiente, el proceso simple de estímulo-respuesta queda sustituido por un acto complejo y mediato [...] (Vygotsky, 1979:69).

De este modo, los signos, en tanto mediaciones, conducen a una transformación de la conducta del ser humano, al crear una nueva relación entre el estímulo y la respuesta, es decir, "se convierten en las causas inmediatas de la conducta" (Vygotsky, 1979:69). Así, el sentido de la mediación que aparece en Vygotsky se encuentra en la línea del aporte que hace Hegel, en cuanto la mediación de los signos conduce hacia otra cosa distinta y reflexionada (en este caso, una respuesta o una conducta) a partir de un primer término: un estímulo. Se puede entrever entonces que un sentido de la mediación es la transformación, no solo del entorno, sino del individuo mismo que transforma su conducta. Dado que los aportes de Vygotsky tienen influencia en el campo de la educación, cabe preguntarse: ¿̇será el aprendizaje la transformación de la conducta del individuo? ¿Será que el estímulo proviene de lo que se enseña?

Cincuenta años más tarde, el rumano Reuven Feuerstein (1921-), doctor en Psicología del Desarrollo, también hizo sus aportes a la construcción de la historia del concepto desde sus campos de estudio: la psicología del desarrollo, la clínica y la cognoscitiva desde una perspectiva transcultural. Aunque sus trabajos datan desde principios de la segunda mitad del siglo XX, en la década del 70, manifiesta un marcado interés por las teorías de la modificabilidad cognoscitiva estructural (MCE) y la experiencia de aprendizaje mediada (EAM) cuyas prácticas lo llevan a desarrollar el "Dispositivo de evaluación de la propensión de aprendizaje" (Learning Propensity Assessment Device -LPAD-), el Programa de enriquecimiento instrumental de Feuerstein (EIF) y la creación de ambientes modificantes. El desarrollo de las teorías de la modificabilidad cognoscitiva estructural y de la experiencia de aprendizaje mediada surgen como respuesta a un interés de ver cómo las personas de bajo rendimiento llegan a ser capaces de modificarse mediante procesos cognitivos.

A pesar de que, en Feuerstein, tampoco se encuentra una definición del concepto mediación, la conceptualización que hace alrededor de la experiencia de aprendizaje mediada deja ver algunos sentidos que tiene el concepto desde este autor. Al respecto señala: "la EAM se define como la calidad de la interacción del ser humano con su ambiente. La EAM es mucho más que un simple modelo pedagógico; conlleva la explicación de los procesos cognoscitivos como subproducto de la transmisión cultural" (Feuerstein, en entrevista con Noguez, 2002:5). Subsiguientemente, señala dos modalidades en las que el hombre 
interacciona con el ambiente: una, la exposición directa a los estímulos y otra, la experiencia de aprendizaje mediada:

La EAM, en la cual la interacción del humano con su ambiente es mediada por otra persona que actúa intencionalmente. Esto transforma los tres componentes de E-O-R [estímulo-organismo-respuesta] de manera significativa en una combinación compatible, donde $\mathrm{H}$ es el humano mediador, $\mathrm{O}$ es el organismo o sujeto del aprendizaje, $\mathrm{R}$ es la respuesta y E representa los estímulos; $\mathrm{H}$ se interpone entre $\mathrm{E}$ y $\mathrm{O}$, así como entre $\mathrm{O}$ y R (Feuerstein, en entrevista con Noguez, 2002:6)

Así las cosas, con este doctor en Psicología, la relación entre el estímulo y la respuesta adquiere la siguiente estructura: $\mathrm{E} \rightarrow \mathrm{H} \rightarrow \mathrm{O} \rightarrow \mathrm{H} \rightarrow \mathrm{R}$. De esta forma, gana importancia la intervención de otra persona (que en el caso de la educación, sería el profesor) que se interpone entre el estímulo (la cultura representada en el saber) y el organismo (el estudiante) y entre éste y su respuesta (el aprendizaje). Así, el aprendizaje se convierte en lo mediato de esta relación, en tanto depende de la acción mediadora del profesor y del estímulo, pero, a la vez, responde a la composición o el acuerdo a que se llega entre la cultura del saber y los estudiantes.

Entonces, con las contribuciones que hace Feuerstein, el concepto mediación va adquiriendo el sentido de ser una acción intencional de un medio, en tanto tiene un propósito, que en el caso de la educación es el aprendizaje. Tal vez, por esto -por el propósito- se cataloga la mediación como una intervención. Pero también se puede advertir que el hecho de que la mediación tenga una intención, quiere decir también que la mediación tiene un sentido.

Por esta misma época, en áreas como la comunicación y el derecho se hicieron aportes importantes a la historia del concepto mediación. Particularmente, en el área de la comunicación, expertos como Manuel Martín Serrano (1940- ), Jesús Martín Barbero (1937- ) y Guillermo Orozco Gómez (1954- ) han hecho amplias contribuciones para la comprensión del concepto.
Se podría decir que es con el español Manuel Martín Serrano con quien se abre un nuevo campo en las ciencias sociales dedicado al estudio de la mediación, cuando en 1970 investigaba en Francia el modo en que la televisión estaba transformando la visión del mundo. Siete años más tarde, publicó el texto La mediación social, en el cual ofrece la teoría y las metodologías adecuadas para el estudio de la mediación, constituyéndose en un referente teórico para el área de la comunicación.

De acuerdo con Martín Serrano, "desde el punto de vista cognitivo, la mediación equivaldría al sistema de reglas y de operaciones aplicadas a cualquier conjunto de hechos, o de cosas pertenecientes a planos heterogéneos de la realidad, para introducir un orden" (Martín, 1977:49). Y agrega posteriormente: "[...] el mediador, por medio de "lo que ocurre" trata de explicar el orden. El suceso sirve para ilustrar una forma de consenso que ofrece un significado estable para interpretar el mundo. El mediador se sirve del acontecer para reproducir el código [... ." (Martín, 1977:53). Así, la mediación, en tanto sistema, es un proceso que establece una lógica común para los hechos cognoscitivos, para dotarlos de sentido, para darles un orden. Por tal razón, afirma:

... se puede hablar de mediación solamente cuando determinados significantes deben asumir determinados significados, y cuando para atribuir los segundos a los primeros, existe un código mediador. O lo que es lo mismo: cuando ciertos objetos del medio humano (materiales o inmateriales) van a ser relacionados con ciertos objetivos, a través de un proceso de interpretación de la realidad que dirigen los comportamientos y las acciones, mediando siempre un proceso cognitivo. La determinación de los códigos mediadores ha constituido, y constituye, uno de los objetos más importantes de las ciencias sociales (Martín, 1977:80).

Se piensa entonces, que en la mediación se relacionan significantes y significados por medio de códigos mediadores, los cuales establecen una lógica común. De ahí que para este español "[...] todos los mediadores comparten una característica: son modelos de integración [...]" (Martín, 
1977:49). Integran significantes y significados, estímulo y respuesta; en fin, integran cosas contrarias. Pero también se vislumbra que la mediación, en tanto es una acción, porta un sentido: desvelar el código de los hechos (de los significantes) y, a la vez, introducir el código para interpretarlos y así lograr un significado estable, una lógica común de los hechos. Así las cosas, para Martín Serrano "la mediación se define como la actividad que impone límites a lo que puede ser dicho, y a las maneras de decirlo, por medio de un sistema de orden" (Martín, 1977:54). Si bien, la mediación impone unos límites para establecer una lógica común entre significantes y significados, ¿de qué dependen esos límites y esa lógica común? Es decir, ¿̇e qué depende la acción de los códigos mediadores? Tal vez, en los aportes de Martín Barbero se pueda encontrar alguna repuesta.

El semiólogo, antropólogo y filósofo español Jesús Martín Barbero, experto en comunicaciones y medios, en 1987 publica el texto De los medios a las mediaciones: comunicación, cultura y hegemonía en el cual mira el proceso de comunicación desde el lugar de la recepción, es decir, desde la apropiación de los contenidos de los medios. Lo importante para Martín Barbero es que el proceso de comunicación se aborde desde las mediaciones y no desde los medios.

Para Martín Barbero las mediaciones son "articulaciones entre prácticas de comunicación y movimientos sociales [...]" (Martín, 1998:257). Y afirma también que "[... las mediaciones, [son], los lugares de los que provienen las constricciones que delimitan y configuran la materialidad social y la expresividad cultural [...]" (Martín, 1998:298). De lo cual se puede comprender que la mediación, al articular las prácticas de comunicación y los movimientos sociales, delimita y configura la cultura. Es por esto que con este comunicador español se redimensiona la cultura en tanto mediación. A propósito, señala lo siguiente:

... en la redefinición de la cultura es clave la comprensión de su naturaleza comunicativa. Estos es, su carácter de proceso productor de significaciones y no de mera circulación de informaciones y por tanto, en el que el receptor no es un mero decodificador de lo que en el mensaje puso en el emisor, sino un productor también (Martín, 1998:291).

Así, la mediación como instancia cultural, se constituye en el lugar desde donde los receptores producen y se apropian del significado y del sentido de los medios. En últimas, es la cultura en tanto mediación la que dota de sentidos a los medios (o a los códigos mediadores) y son estos sentidos los que establecen la lógica común entre los significantes y los significados, lo que al mismo tiempo redefine la cultura. De modo que la mediación es una cuestión cultural.

En este contexto de la comunicación y en tiempos más contemporáneos, el comunicador mejicano y doctor en Educación Guillermo Orozco Gómez, también hace sus aportes al concepto mediación, reafirmando los sentidos antes señalados para el concepto. Es así como plantea que "[...] las mediaciones hay que entenderlas como procesos estructurantes provenientes de diversas fuentes, que inciden en los procesos de comunicación y conforman las interacciones comunicativas de los actores sociales" (Orozco, 2002:26). En consecuencia, la mediación se da en la comunicación y al mismo tiempo, dispone la interacción de quienes participan en ella.

Entonces, los sentidos que guarda el concepto mediación desde el ámbito de la comunicación es de ser una instancia cultural y un proceso estructurante que pone límites a la comprensión de los significantes y los significados con el fin de que los receptores produzcan y se apropien de una lógica común desde la cultura que se media. Como proceso estructurante, articula las partes contrarias en un todo que es la comunicación, para incidir en ella misma. Tal vez, lo que se guarda en el fondo del concepto mediación es la transferencia de sentidos en tanto comunicación.

A la par en que se hacían estas construcciones desde el campo de la comunicación, en el área del derecho también iba surgiendo un interés hacia la mediación, como una nueva institución encaminada a la resolución alternativa de conflictos. Este interés surgió en Estados Unidos, después de la segunda mitad del siglo XX, como consecuencia de una nueva sensibilidad, contraria a la violencia, 
que cobró fuerza al término de la Segunda Guerra Mundial.

Desde el campo del derecho, se comprende la mediación como la intervención que hace un tercero para ayudar a otros -en conflicto- a establecer un acuerdo. Son varios los autores que a principios de los años 90 presentan una definición al concepto, pero en esta ocasión se trae la definición dada por la abogada y experta en mediación Karen Grover Duffy:

"Mediación" es la intervención en un conflicto de una tercera parte neutral que ayuda a las partes opuestas a manejar o resolver su disputa. La tercera parte imparcial es el mediador, quien utiliza diversas técnicas para ayudar a los contendientes a llegar a un acuerdo consensuado con el fin de resolver su conflicto. [...] Se supone que los mediadores no fuerzan ni imponen la resolución. En lugar de ello, un mediador capacita a los contendientes para llegar a su propio acuerdo sobre el modo de resolución del conflicto, propiciando la discusión cara a cara, resolviendo el problema y desarrollando soluciones alternativas (Grover, 1996:52).

De esta forma, el concepto mediación se reafirma en los sentidos adquiridos anteriormente, pero también gana nuevos matices que dan otras orientaciones para interpretar el concepto. Así, la mediación bajo la mirada del derecho se comprende como la ayuda que proporciona un tercero, para que dos o más partes en conflicto lleguen a un acuerdo consensuado, es decir, que sea el resultado del común acuerdo de las partes implicadas y no el producto de la imposición del mediador. ¿Será entonces, que en el concepto mediación subyace el sentido de la proximidad de contrarios en tanto se establecen acuerdos comunes? ¿̇Implicará el establecimiento de acuerdos comunes una comprensión de las partes?

Al respecto, María José Lucerga Pérez propone la mediación como "una instancia metacomunicativa que transciende o instaura distancias entre los participantes en una interacción" (Lucerga, 1997:119). Consecuentemente, la mediación adquiere el sentido de la distancia, en tanto puede posibilitar el encuentro entre los participantes de la interacción o también puede alejarlos alterando la comunicación. Pero aunque la mediación puede crear distancias, la esencia de ella es aproximar a las partes para alcanzar el acuerdo consensuado; así lo señala Martínez en 1999, en el libro Mediación y resolución de conflictos (Martínez, 1999:117).

El sentido del acuerdo consensuado que guarda el concepto mediación, lo vincula directamente con el sentido de la comprensión. Es decir, en la intervención que hace el mediador, más que buscar el acuerdo en sí mismo, lo que se busca es que las partes se comprendan, conforme lo advierte Martínez:

... es importante señalar que la mediación, además de aspirar a que las partes se reconcilien, busca que sean éstas las que diseñen de manera conjunta soluciones posibles al conflicto, que las conduzcan a la firma de un acuerdo satisfactorio para todos. De esta manera, podemos decir que la mediación es una técnica más ambiciosa que la conciliación, porque aspira a que las partes se comprendan (Martínez, 1999:50).

Así las cosas, en el acuerdo consensuado subyace la comprensión de las partes. Aunque se podría decir que la mediación dentro del campo jurídico tiene sus antecedentes en dos áreas: en la práctica jurídica tradicional, en la figura de la "composición amigable" (Martínez, 1999:12) y en el campo empresarial, en la figura del tercero que interviene en la solución de conflictos laborales (Bush y Folger, 1996:19-20), de acuerdo con el aporte de Delfina Linck, la mediación en el área del derecho también se relaciona con la comunicación (Linck, 1996:135). En 1996, en el artículo Mediación y comunicación señala lo siguiente:

Habitualmente, las partes de un conflicto tienden a pensar que la diferencia principal que los separa y los enfrenta radica en los contenidos. Quisiéramos mostrar cómo la capacidad y la oportunidad que el mediador tienen para ayudar a lograr un acuerdo radica antes que nada en la posibilidad que le dan las partes de intervenir en la comunicación entre ellas, modificando la forma en que se puede y debe comunicar, incidiendo en la manera en que se trasmiten los contenidos de información y por ende 
en la definición de la relación entre las partes (Linck, 1996:136).

Por lo tanto, así como se apuntaba desde el contexto de la comunicación, la mediación ocurre en la comunicación e incide en ella, pero lo que busca fundamentalmente es componerla -porque se parte de que en un conflicto la comunicación está rota-. O sea que la mediación es un asunto de forma: de la forma como se comunican las cosas. Asimismo, también lo asegura Suárez: "la comunicación es un tema central del proceso de la mediación [...]" (Suárez, 1996:91). Y posteriormente agrega: "la mediación surge para conducir problemas de comunicación, y esta conducción se resuelve "en" la comunicación" (Suárez, 1996:95).

Entonces, si la función de la mediación es facilitar, incidir y componer la comunicación a través del diálogo, ¿̇será que el lenguaje adquiere un sentido fundamental para la mediación? ¿Será que el lenguaje influye en la forma en que se comunican las partes? Al respecto afirma Linck: "[...] las intervenciones verbales del mediador serán efectivas en la medida en que estén formuladas en un lenguaje adecuado a las circunstancias sociales y culturales de las personas que participan de la mediación" (Linck, 1996:139). Así, en tanto el mediador emplee el lenguaje adecuado en el diálogo, es decir, un lenguaje acorde con las circunstancias culturales de las partes, será posible llegar a acuerdos entre ellas y, de este modo, posibilitar la comprensión de las cosas y restablecer la comunicación.

El concepto mediación trae, de tiempo atrás y entre muchos otros, un sentido: el sentido de la transformación. Esto ya lo anunciaba Vygostky al afirmar que por la mediación de los signos se produce una transformación en la conducta del ser humano. Ahora, en el ámbito del derecho, Bush y Folger en el libro La promesa de la mediación (1996) sostienen también que la dimensión más importante del proceso de mediación es el desarrollo del potencial de cambio que cada persona inmersa en un conflicto lleva consigo, descubriendo sus propias habilidades y desarrollando una mayor apertura hacia las otras partes litigantes. Para estos americanos expertos en resolución alternativa de conflictos, "[...] la palabra trans- formación significa un cambio o refinamiento de la conciencia y el carácter de los seres humanos individuales [... |" (Bush y Folger, 1996:52). ¿Estará pues la transformación de las partes asociada con la comprensión de ellas? Posiblemente.

Entonces, tenemos que desde el ámbito jurídico, el concepto mediación se comprende como la intervención de un tercero para ayudar al establecimiento de un acuerdo consensuado, en el marco de la comunicación. Es decir, la mediación como un proceso comunicativo, por medio del lenguaje adecuado y del diálogo, transforma y acorta la distancia entre las partes en conflicto para componer la comunicación, en tanto se alcanzan acuerdos y se logra la comprensión de los involucrados en el conflicto.

Estos sentidos que toma el concepto mediación desde el campo del derecho van permeando otras áreas como la educación, desde la cual se habla de la mediación escolar. De acuerdo con Aguirre, "la mediación es un sistema alternativo de gestión de conflictos. Es la intervención no forzada de una tercera persona imparcial (la mediadora o el mediador) que ayuda a las personas de la comunidad escolar en conflicto a resolver dicho conflicto o a transformarlo por sí mismas" (Aguirre, 2005:32). Se trata pues de formar algunos estudiantes como mediadores que ayuden posteriormente en la solución de las controversias que se presenta dentro de las aulas de clase.

Sin embargo, en el marco educativo también se encuentran otras aportaciones al concepto mediación, que no se ubican dentro de la línea de la solución alternativa de conflictos, sino que son construcciones que se hacen desde una perspectiva didáctica, curricular y pedagógica. Veamos:

En 1989, en Francia, Louis Not publica el libro La enseñanza dialogante el cual es una propuesta de educación basada en la convicción de que el discurso del profesor será formativo en la medida en que el alumno reciba los mensajes magistrales, los reconstruya y los integre en sus propias estructuras y necesidades mentales. Desde el punto de vista práctico de la enseñanza dialogante, la mediación didáctica "consiste en suministrar al alumno la información de la que no dispone y que no podría procurarse por sus propios medios; 
después, en ayudarle a transformarla en conocimiento" (Not, 1992:83). Se entiende entonces, la mediación -en el contexto de la educación- como la intervención del profesor para suministrar información a los estudiantes y ayudar a transformarla en conocimiento, es decir, para ayudar en su aprendizaje. Al parecer, este concepto mediación didáctica se ubica dentro de las contribuciones que hace Feuerstein respecto a la experiencia de aprendizaje mediada. Así, el concepto mediación guarda el sentido de proporcionar algo de una parte a otra, que sin la intervención del mediador (o sea del medio), no se podría acceder a ello. Pero no se trata solo de acceder a algo que no se podía acceder antes, sino de ayudar para que ese acceso a lo nuevo sea comprensible. Cabe preguntarse entonces, realmente ċa qué se accede con la mediación?, ¿̇se accede a una información? Pero, además, ¿̇supone la mediación un "tratamiento" del algo que se proporciona para posibilitarle al estudiante su acceso y comprensión?

Por esta época Guillermo Orozco Gómez, quien también hizo sus aportes a la conceptualización de la mediación desde el ámbito de la comunicación, ahora desde el campo de la educación, hace su contribución. De acuerdo con Orozco, "por mediaciones se entiende [...] el conjunto de elementos que influyen el proceso de aprendizaje y conforman su producto final, tanto provenientes del desarrollo cognoscitivo del sujeto como de su cultura [...]" (Orozco, 1989:13). Así, la mediación es un conjunto de elementos cognoscitivos y culturales que intervienen en el aprendizaje. Un poco, en esta misma línea, se encuentra el aporte de Mejía, para quien "el currículo entendido como texto dotado de sentido, se concibe como una mediación entre el mundo del conocimiento [...] y la formación de las personas para las cuales se ha concebido tal currículo [...]" (Mejía, 2000:25). De este modo, el currículo, como un conjunto de elementos cognitivos y culturales, posibilita la interacción entre el mundo de la ciencia y del arte y los estudiantes, para favorecer el aprendizaje. Entonces, si el currículo es un texto dotado de sentidos y también es una mediación, podría pensarse que la mediación se constituye también en un texto que porta sentidos, de ahí, que en el fondo del concepto perviva la transferencia de sentidos, la comunicación, el lenguaje. Con la mediación pues, se accede al sentido de las cosas.

De otro lado, Daniel Prieto Castillo en sus libros La comunicación EN la educación publicado en 2004 y La mediación pedagógica publicado en 2007. en coautoría con Francisco Gutiérrez Pérez, presenta algunas definiciones del concepto mediación. Para Prieto, "la mediación construye puentes para el aprendizaje desde todos los horizontes de vida y de creación del ser humano" (Prieto, 2004:115). Es por esto que Prieto denomina mediación pedagógica, a la mediación que es capaz de promover y acompañar el aprendizaje (Prieto, 2000:29). Pero tal vez, en el texto publicado en 2007, presenta una conceptualización un poco más elaborada acerca de la mediación. En este libro expresa:

Entendemos por mediación pedagógica el tratamiento de contenidos y de las formas de expresión de los diferentes temas a fin de hacer posible el acto educativo, dentro del horizonte de una educación concebida como participación, creatividad, expresividad y relacionalidad. Hablamos de mediación en el estricto sentido de mediar entre determinadas áreas del conocimiento y de la práctica y quienes están en situación de aprender algo de ellas (Gutiérrez y Prieto, 2007:14).

Por lo tanto, a la luz de estos doctores en Filosofía y en Comunicación, la mediación se entiende como un proceso por el cual el docente trata los contenidos y las formas de expresión de ellos, para facilitar el aprendizaje. Al respecto, afirman: "la mediación pedagógica busca abrir el camino a nuevas relaciones del estudiantes: con los materiales, con el propio contexto, con otros textos, con sus compañeros de aprendizaje, incluido el docente, consigo mismo y con su futuro" (Gutiérrez y Prieto, 2007:15). Entonces, el tratamiento de los contenidos y la manera de expresarlos lo que busca es abrir el camino o establecer puentes que le posibiliten al estudiante crear nuevas relaciones con el saber y el contexto que le rodea. Por consiguiente, la mediación pedagógica guarda el sentido de ser un proceso que establece puentes 
entre los contenidos y los sujetos del aprendizaje, con el fin de posibilitar otras relaciones entre ellos, para componer la comunicación.

Como se observa, pues, son diversos los campos desde los cuales se hacen aportes a la conceptualización de la mediación, aportes que se incorporan al concepto en tiempos diferentes, pero que en conjunto hacen posible desvelar un sentido común oculto en el concepto. Así las cosas ¿qué es mediación?

La aproximación histórica al concepto permite comprender la mediación como un proceso dialéctico que busca instaurar, con la ayuda de un medio (un tercero) y en el marco de una cultura, una lógica común que posibilite la comunicación entre dos partes que tienen lógicas y formas diferentes de comunicarse. Como proceso dialéctico, relaciona las partes -que están dadas de manera independiente- para establecer un acuerdo consensuado, a partir de la comunicación de sentidos que, como puentes, vincula las partes y acorta la distancia que había entre ellas para comprenderse, transformarse y comunicarse conforme la cultura. De ahí, que el lenguaje se convierta en un factor fundamental para la mediación; el lenguaje debe estar acorde a las partes en conflicto. La mediación lleva, pues, a entender lo que debe ser entendido, a decirlo de la manera que debe ser dicho, a ver cosas que antes no se habían visto, a acceder a cosas a las que antes no se podía acceder por sí solo. Así, la mediación compone o restablece la comunicación y relación de las partes. Pero también como proceso dialéctico, el acuerdo o la lógica común que se instaura entre las partes se deriva de la cultura marco en que se da la mediación, por lo tanto, el acuerdo es producto de la transmisión de sentidos de la cultura, transmisión que se realiza por medio de los vínculos que se establecen por el diálogo entre las partes. De modo, que el acuerdo es mediato, es reflexionado según la cultura (por esto, la mediación compone, en tanto crea algo nuevo, algo que no existía), lo que permite modificar la conducta de las partes y transformarlas para insertarse en dicha cultura. En consecuencia, la mediación instaura la cultura y, a su vez, la cultura instaura la mediación.

\section{Conclusiones}

- Aunque desde la Antigüedad perviven sentidos de la mediación, se presume que es con Hegel que surge el concepto, al definir la mediación como un comienzo y un progreso hacia un segundo término, pero lo segundo, sólo es en tanto se ha llegado a él a partir de otro que le es opuesto.

- Desde el campo de la comunicación el concepto de mediación se comprende como una instancia cultural y un proceso estructurante que pone límites a la comprensión de los significantes y los significados con el fin de que los receptores produzcan y se apropien de una lógica común desde la cultura que se media.

- Desde el campo del derecho se entiende el concepto mediación como la intervención de un tercero para ayudar al establecimiento de un acuerdo consensuado, en el marco de la comunicación.

- Desde el campo de la educación se entiende el concepto mediación como un proceso que establece puentes entre los contenidos y los sujetos del aprendizaje, para componer la comunicación entre las partes y posibilitar otras relaciones entre el contenido y los estudiantes.

- La mediación como un proceso dialéctico busca instaurar, con la ayuda de un medio (un tercero) y en el marco de una cultura, una lógica común que posibilite la comunicación entre dos partes que tienen lógicas y formas diferentes de comunicarse.

\section{Referencias bibliográficas}

Aguirre, A. (2005). La mediación escolar: una estrategia para abordar el conflicto. Caracas: Laboratorio Educativo. Recuperado el 5 de marzo de 2010. Disponible en http://books.google.com.co/books?id=4jrAO55Ghw OCEprintsec $=$ frontcoverEdq $=\mathrm{La}+$ mediaci\%C3\%B3 $\mathrm{n}+$ escolar: + una +estrategia + para + abordar + el $+\mathrm{c}$ onflicto $\mathcal{E} \mathrm{d}=1 \mathrm{\#} \mathrm{v}=$ onepage $\mathcal{E} \mathrm{q}=\mathcal{E} \mathrm{f}=$ false 
Aristóteles. (1975). Órganon: escritos de lógica. La Habana: Editorial de Ciencias Sociales.

Bush, R. A. B. E Folger, J. P. (1996). La promesa de la mediación: cómo afrontar el conflicto mediante la revalorización y el reconocimiento. Argentina: Granica.

Ferrater Mora, J. (1994). Diccionario de filosofía. (Ed. rev y aum.) España: Ariel

Grover D., K. (1996). Introducción a los programas de mediación comunitaria: pasado, presente y futuro. En: Grover D., K.; Grosch, J. W. \& Olczak, P. V. (Comps.) La mediación y sus contextos de aplicación: una introducción para profesionales e investigadores. (pp. 51-65) Buenos Aires: Paidós.

Gutiérrez P., F. \& Prieto C. D. (2007). La mediación pedagógica: apuntes para una educación a distancia alternativa. Buenos Aires: La Crujía.

Hegel, G. W. F. (1968). Ciencia de la lógica. Argentina: Ediciones Solar S.A.

Hegel, G. W. F. (1973). Enciclopedia de las ciencias filosóficas. Argentina: Porrúa.

Hegel, G. W. F. (2006). La lógica de la enciclopedia. Buenos Aires: Levitan.

Linck, D. (1996). Mediación y comunicación. En: Gottheil, J. E Schiffrin, A. (Comps.) Mediación: una transformación en la cultura. (pp. 135-151) Buenos Aires: Paidós.

Lucerga P., M. J. (1997). Sobre árbitros, traductores y celestinas: la figura del mediador como instancia metacomunicativa. Revista de Investigación Lingüística 1(1):111-134.

Martín Barbero, J. (1998). De los medios a las mediaciones: comunicación, cultura y hegemonía. Bogotá: Convenio Andrés Bello.

Martín Serrano, M. (1977). La mediación social. Madrid: Akal.
Martínez de M., B. (1999). Mediación y resolución de conflictos. México: Paidós.

Mejía B., L. (2000). El currículo como mediación cultural y pedagógica. Hojas Universitarias, 49:24-31.

Noguez, S. (2002). El desarrollo potencial de aprendizaje. Entrevista a Reuven Feuerstein. Revista Electrónica de Investigación Educativa, 4 (2). Recuperado el 7 de marzo de 2010. Disponible en http://redie.uabc.mx/ contenido/vol4no2/contenido-noguez.pdf

Not, L. (1992). La enseñanza dialogante: hacia una educación en segunda persona. Barcelona: Herder

Orozco G., G. (1989). Mediaciones cognoscitivas y videos educativos: un reto para la producción del aprendizaje. Signo y pensamiento, 14:9-19.

Orozco G., G. (2002). Mediaciones tecnológicas y des-ordenamientos comunicacionales. Signo y pensamiento, 41(21):21-33.

Platón. (1984). Diálogos de Platón: Timeo o de la Naturaleza. Bogotá: Ediciones Universales.

Prieto C. D. (2004). La comunicación EN la educación. $2^{\mathrm{a}}$. Ed. Buenos Aires: La Crujía.

Prieto C., D. (2000). Mediación pedagógica y contexto digital. Revista Universidad Pontificia Bolivariana, 48 (147):27-38.

San Agustín de Hipona. (1824). Las confesiones de nuestro gran padre San Agustín. Libro II. Cuarta edición. Madrid: Imprenta de Don Ramón Verges. IVersión electrónical. Recuperado el 11 de febrero de 2010. Disponible en http://books.google.com.co/ books?id=w-3K8gjXsmACEpg $=$ PA220\&dq $=$ media ci\%C3\%B3n+\%26+san + agust\%C3\%ADn + de +hi

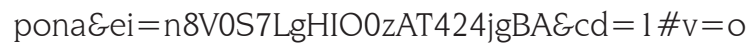
nepageE $\mathrm{q}=$ mediaci\%C3\%B3nEf $=$ false

Vygotsky, L. S. (1979). El desarrollo de los procesos psicológicos superiores. Barcelona: Crítica. 
